\title{
Genetic and environmental information in goat milk Fourier transform infrared spectra
}

\author{
B. S. Dagnachew, ${ }^{\star 1}$ A. Kohler, $† \ddagger \S$ and T. Ådnøy $¥$ \\ ${ }^{*}$ Department of Animal and Aquacultural Sciences, \\ †Department of Mathematics and Technology, and \\ †Center for Integrative Genetics (CIGENE), Norwegian University of Life Sciences, PO Box 5003, N-1432 Ås, Norway \\ §Nofima AS, PO Box 210, N-1430 Ås, Norway
}

\begin{abstract}
Fourier transform infrared (FTIR) spectroscopy is often used in prediction of major milk components in genetic evaluation of dairy animals. Until now genetic variability of goat milk FTIR spectra has only been known indirectly through their contribution to the major milk components. In this study, genetic and environmental components of goat milk FTIR spectra were examined directly. A data set containing 83,858 milk FTIR spectral observations belonging to 29,320 Norwegian dairy goats of 271 herds was used for the study. Principal components analysis was applied on both unprocessed and preprocessed spectral data, and new traits (latent traits) were defined because a multitrait analysis of all spectral variables for variance components could not be done. Eight and 7 latent variables, explaining approximately $99 \%$ of the total unprocessed and preprocessed spectral variation, respectively, were kept from the principal components analysis for genetic analysis. Genetic and environmental variance components were estimated for the latent traits using restricted maximum likelihood. Genetic-to-total phenotypic variance ratios (heritabilities) of the latent traits were between 0.011 and 0.285 for the unprocessed spectra and between 0.135 and 0.262 for the preprocessed spectra. The estimated variance components for the latent traits were back transformed to the spectral variables. Heritabilities of these spectral variables ranged from 0.018 to 0.408 and variance ratios of the permanent environmental effects of goats were between 0.002 and 0.184 of the phenotypic spectral variation. Highto-moderate heritabilities were observed in particular in spectral regions related to major milk components (fat, lactose, and protein): between 1,030 and 1,300 $\mathrm{cm}^{-1}, 1,500$ and $1,600 \mathrm{~cm}^{-1}, 1,700$ and $1,800 \mathrm{~cm}^{-1}$, and 2,800 and $3,000 \mathrm{~cm}^{-1}$. Our results confirmed that a
\end{abstract}

Received July 24, 2012.

Accepted February 18, 2013.

${ }^{1}$ Corresponding author: binyam.dagnachew@umb.no substantial amount of genetic variation exists in goat milk FTIR spectra. Not all spectral variations are of genetic origin; some FTIR regions are highly influenced by herd test-day variation. The study also pointed out the possibility of using FTIR spectra as a monitoring tool in herd management.

Key words: latent trait, principal components analysis, Fourier transform infrared spectra, heritability

\section{INTRODUCTION}

Implementation of animal breeding schemes aiming at improving milk quality requires obtaining detailed milk composition information and using it for breeding. However, in most genetic-evaluation programs for dairy animals only few major milk components (e.g., fat and protein) are included. Costly and time-consuming chemical analyses to measure other milk components limit their inclusion in breeding programs.

In most genetic evaluation programs for dairy animals, major milk components are predicted from infrared (IR) spectra. Applications of IR spectroscopy to milk analysis dates back to the early 1960s (Goulden, 1964). The first applications were based on transmission spectroscopy (developed under dispersive instruments). Then, the technology moved to use of interference filters to increase the energy and to facilitate sample throughput (Andersen et al., 2002). The use of fixed-wavelength filter instruments restricts the spectral ranges corresponding to the absorption of the major milk components, so use of the complete IR spectra of the products analyzed is not possible (van de Voort, 1992).

Fourier transform IR (FTIR) spectroscopy was developed to overcome the limitation encountered with the filter instruments. It provides a fast and powerful tool for improving vibrational spectroscopy analysis. It has several advantages over filter-based spectroscopy methods: improved signal-to-noise ratio, multiplexing capabilities, significant reduction in scan time, higher energy throughput, and superior wavelength accuracy, among others (van de Voort, 1992). 
Fourier transform IR spectroscopy has been used for a wide range of applications: quantification of milk components (Luinge et al., 1993), detection of milk from different species (Nicolaou et al., 2010), detection of specific milk sugars (Hansen et al., 1999), prediction of FA composition in milk (Soyeurt et al., 2006; Afseth et al., 2010), determination of protein composition in milk (Hewavitharana and van Brakel, 1997; Rutten et al., 2011), determination of cheese composition (Rodriguez-Saona et al., 2006), and glycerol prediction in wine (Nieuwoudt et al., 2004), among others.

Milk FTIR spectra may reflect both genetic and environmental variations of milk components. In a recent study, the genetic variability of bovine milk components based on mid-infrared spectra are investigated (Soyeurt et al., 2010). The study reported that some regions of the mid-infrared spectra are more genetically determined than other. Until now, to the best of our knowledge, genetic and environmental variability of the goat milk FTIR spectra have not been investigated.

All details of information on milk composition traits are not predicted and used in most genetic-evaluation programs for dairy animals. Milk FTIR spectra could possibly give more useful information on how the quality of milk is influenced by genetic and environmental factors. This could be used to define new traits and also used as a herd management monitoring tool to detect aberrations due to feeding and other environmental changes. Everett et al. (1994) and Mayeres et al. (2002) suggested modifying the herd test-day (HTD) effect of a test-day model in a manner to allow use of its solutions in herd management. They proposed replacing the HTD effect by 3 effects associated with a herd: fixed effect of herd test year (HTY), fixed effect of herd test month (HTM), and random effect of HTD (HTDr). This modification allows prediction of future herd-specific effects, hence monitoring unex- pected variation. The main objective of this study was to investigate genetic and environmental variability of goat milk FTIR spectra.

\section{MATERIALS AND METHODS}

\section{FTIR Spectra Data}

In the Norwegian Dairy Goat Control recording system, daily milk yield is to be recorded at least 5 times per farm per year. Of the 5 recording days, at least $3 \mathrm{~d}$ of samples of individual goat milk should be analyzed for major milk components (fat percentage, protein percentage, lactose percentage, SCC, FFA, and urea content). The milk samples are analyzed by MilkoScan CombiFoss 6500 instrument (Foss Electric A/S, Hillerød, Denmark) and the components are predicted using equations applied to the spectral data. The predictions are transferred to the Norwegian Dairy Goat Control database. Raw spectral data have also been stored in a database for research and development purposes.

For this study, 2 yr (2007 and 2008) of raw goat milk FTIR spectra data were used. The data set included 83,858 FTIR spectra observations belonging to 29,320 Norwegian dairy goats. The data set was divided into 2 data sets: calibration and validation, randomly, for testing prediction ability of the model on a separate data set. The validation data set contained 9,000 samples, whereas the remaining 74,858 were used for variance components estimation and model calibration. The structure of the data set used in this study is presented in Table 1.

A pedigree file containing all animals with records was available. Their ancestors were traced back as far as possible, and the final pedigree file contained 59,419 individuals.

Table 1. Data structure: number of herds, goats, and individual test Fourier transform infrared (FTIR) spectra

\begin{tabular}{|c|c|c|c|c|c|}
\hline Data set & Year & Lactation $^{1}$ & Herds & Goats & Tests \\
\hline \multirow[t]{7}{*}{ Calibration } & \multirow[t]{3}{*}{2007} & 1 & 249 & 9.938 & 19,294 \\
\hline & & 2 & 247 & 8,663 & 17,472 \\
\hline & & 3 & 160 & 657 & 1,364 \\
\hline & \multirow[t]{3}{*}{2008} & 1 & 249 & 10,219 & 17.979 \\
\hline & & 2 & 247 & 9,191 & 17,063 \\
\hline & & 3 & 189 & 862 & 1,686 \\
\hline & Both & & 271 & 28,260 & 74,858 \\
\hline \multirow{7}{*}{ Validation } & \multirow{3}{*}{2007} & 1 & 245 & 2,175 & 2.342 \\
\hline & & 2 & 232 & 1,918 & 2,083 \\
\hline & & 3 & 91 & 159 & $\begin{array}{r}2,000 \\
180\end{array}$ \\
\hline & \multirow[t]{3}{*}{2008} & 1 & 244 & 1,951 & 2,093 \\
\hline & & 2 & 239 & 1,925 & 2,095 \\
\hline & & 3 & 96 & 189 & 207 \\
\hline & \multirow[t]{2}{*}{ Both } & & 271 & 7,784 & 9,000 \\
\hline Total & & & & 29,320 & 83,858 \\
\hline
\end{tabular}

${ }^{1}$ The numbers indicate lactation groups. The lactation group 3 includes lactation number 3 and above. 


\section{Selection of FTIR Spectra}

Examples of raw FTIR spectra are shown in Figure 1A. Due to the high proportion of water in milk, both the $\mathrm{O}-\mathrm{H}$ bending region (between 1,600 and 1,700 $\mathrm{cm}^{-1}$ ) and the $\mathrm{O}-\mathrm{H}$ stretching region (above $3,020 \mathrm{~cm}^{-1}$ ) were more or less opaque to IR light in milk samples (Afseth et al., 2010). These 2 regions (accounting for 536 spectral data points) were omitted and the remaining 524 spectral data points (926 to $1,618 \mathrm{~cm}^{-1}$ and 1,705 to $3,025 \mathrm{~cm}^{-1}$ ) were selected for further analysis.

\section{Preprocessing of FTIR Spectra}

Genetic analysis was performed on both unprocessed and preprocessed FTIR spectra. Analysis on the unprocessed spectra was carried out on the selected 524 spectral data points. Preprocessing of the spectra was done using extended multiplicative signal correction (EMSC). Extended multiplicative signal correction was used to remove additive baseline variation and a scaling variation due to optical path length difference multiplicative problems (Kohler et al., 2009). Prior to preprocessing, the spectral region between 1,801 and $2,600 \mathrm{~cm}^{-1}$ was removed because no specific bands or useful chemical information exist in this region (Figure 1A; Andersen et al., 2002; Iñón et al., 2004). Extended multiplicative signal correction was applied on the remaining 262 spectral data points. The multiplicative parameter (b) of EMSC was directly related to the DM content in milk samples (Kohler et al., 2010) and was stored for genetic analysis alongside with preprocessed spectra. Figure 1B presents EMSC preprocessed milk FTIR spectral data.

\section{Dimension Reduction (Definition of Latent Traits)}

Direct genetic analysis of all spectral variables simultaneously was not possible due to computational limitations. To reduce the dimension of spectral variables,

(A)

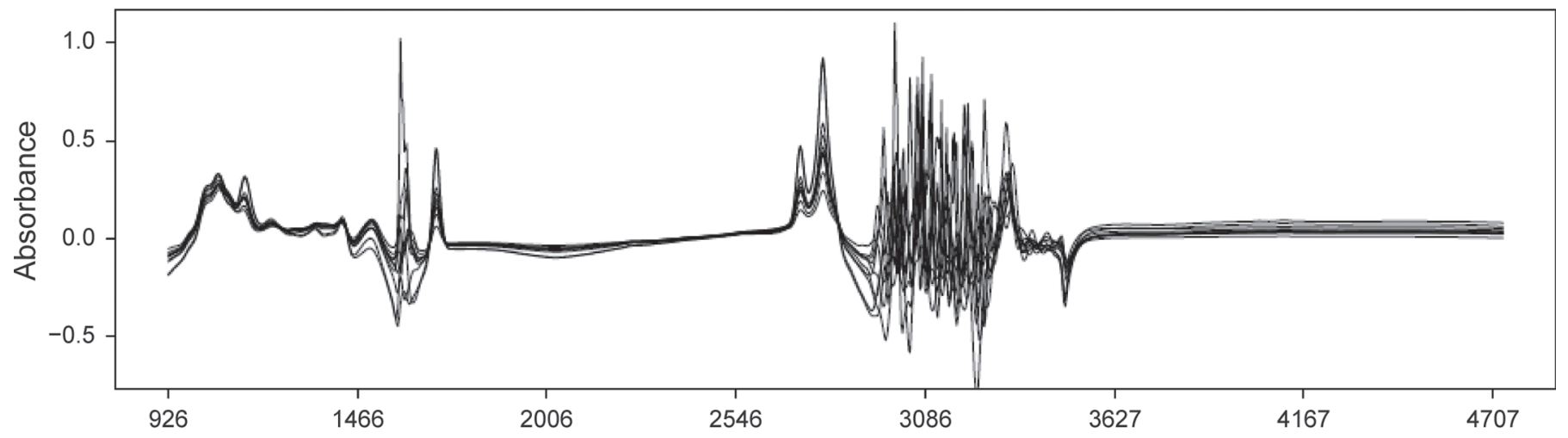

(B)

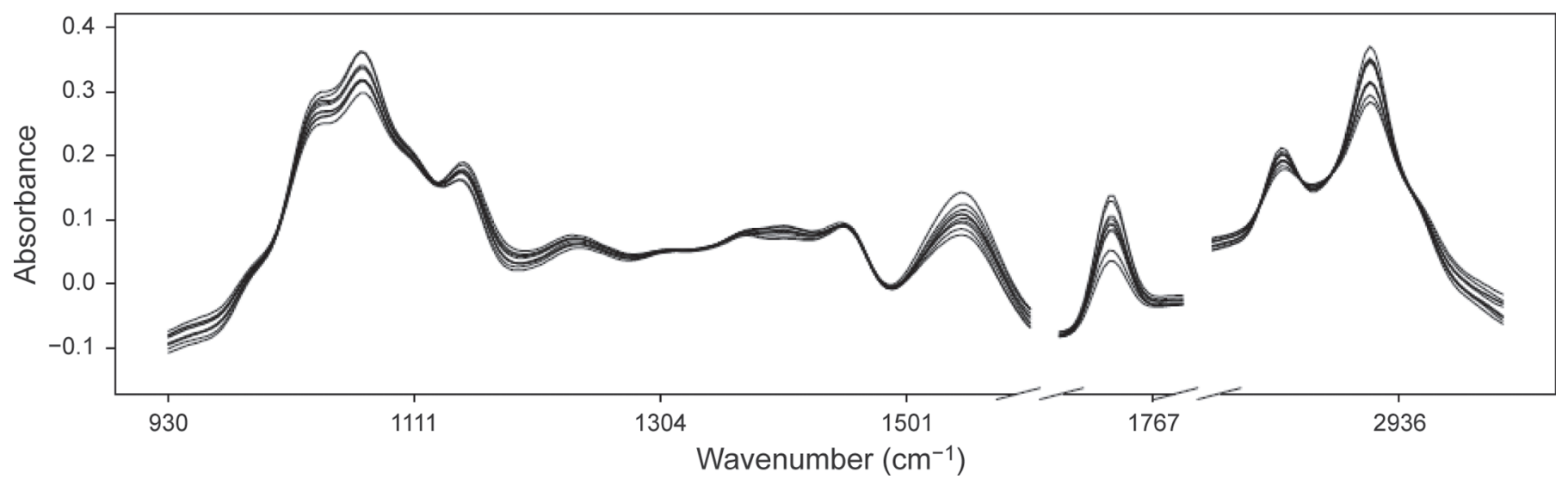

Figure 1. Example of infrared spectra for 10 goat milk samples obtained using a MilkoScan CombiFoss 6500 instrument (Foss Electric A/S, Hillerød, Denmark). (A) Unprocessed absorbance of milk Fourier transform infrared (FTIR) spectra including O-H stretching and bending regions. (B) Extended multiplicative signal correction (EMSC) preprocessed absorbance of milk FTIR spectra without O-H stretching and bending regions and spectral region between 1,801 and $2,600 \mathrm{~cm}^{-1}$. 
principal components analysis (PCA) was carried out on the selected spectral data (i.e., 524 for unpreprocessed spectra and 262 for preprocessed spectra). The goal of PCA is to find a set of fewer components that explain as much of the variance of the original data as possible (Martens and Næs, 1989). These components are formulated as a linear combination of the original variables. The contributions of the original variables to each component are given by a set of eigenvectors (loadings) and the amount of variance retained by each component is given by its eigenvalue.

Let $\mathbf{Y}_{(\mathrm{N} \times \mathrm{K})}$ be a matrix of the selected FTIR spectral data, where $\mathrm{N}$ is the number of observations and $\mathrm{K}$ is 524 for unprocessed and 262 for preprocessed spectra. Principal components analysis for $\mathbf{Y}_{(\mathrm{N} \times \mathrm{K})}$ is expressed as follows:

$$
\mathbf{Y}_{(\mathrm{N} \times \mathrm{K})}=\mathbf{T}_{(\mathrm{N} \times \mathrm{M})} \mathbf{E}_{(\mathrm{M} \times \mathrm{K})}^{\prime}+\mathbf{F}_{(\mathrm{N} \times \mathrm{K})},
$$

where $\mathrm{M}$ is the number of components extracted $(\mathrm{M} \leq$ $\mathrm{K}), \mathbf{T}_{(\mathrm{N} \times \mathrm{M})}$ represents a score matrix of the $\mathrm{M}$ extracted components, $\mathbf{E}_{(\mathrm{M} \times \mathrm{K})}^{\prime}$ represents the transpose of a loading matrix of the $\mathrm{M}$ components, and $\mathbf{F}_{(\mathrm{N} \times \mathrm{K})}$ represents the unmodeled residual after the $\mathrm{M}$ components are extracted from $\mathbf{Y}_{(\mathrm{N} \times \mathrm{K})}$. The number of components $(\mathrm{M})$ is determined based on the proportion of total variance of the spectra explained. Principal components analysis was performed on the correlation matrix of $\mathbf{Y}_{(\mathrm{N} \times \mathrm{K})}$ using the PROC PRINCOMP function of SAS (SAS Institute, 2004). The scores $\left(\mathbf{T}_{(\mathrm{N} \times \mathrm{M})}\right)$ are considered as $\mathrm{M}$ new traits and henceforth they are referred to as latent traits $(\mathbf{L T})$.

\section{Precorrection}

Prior to estimation of variance components for the LT, they were precorrected for some fixed effects because otherwise there would be too many effects to estimate in the multitrait model. The M LT were corrected for the fixed effect of herd region (12 levels), fixed effect of age at kidding ( 5 levels), fixed effect of number of lactation (3 levels), fixed effect of kidding season (3 levels), and fixed effect of stage of lactation (4 covariables; Ali and Schaeffer, 1987). The precorrection was done through fitting LT in a linear model and collecting the residuals:

$$
\mathbf{t}=\mathbf{C f}_{c}+\mathbf{t}_{c},
$$

where $\mathbf{t}$ is a vector of the observed LT for all samples (with LT of one sample on top of the other; see Appendix A); $\mathbf{f}_{c}$ is a vector of fixed effects of herd region, age at kidding, lactation number, kidding season, and stage of lactation for each LT; $\mathbf{C}$ is a design matrix; and $\mathbf{t}_{c}$ is a vector of residuals (henceforth referred to as precorrected LT). The subscript $c$ is used to indicate precorrected.

\section{Model}

Use of HTD contemporary groups in test-day genetic evaluation models allows unbiased comparison of breeding animals (Ptak and Schaeffer, 1993). However, it has the shortcoming that it is not predictable (Mayeres et al., 2002). Everett et al. (1994) and Mayeres et al. (2002) suggested an alternative modeling of HTD effect to allow prediction of future test-day measurements. They proposed replacing the HTD effect with 3 effects: HTY, HTM, and HTDr. In the present study, the HTM effect was modified to a fixed effect of HTM period because less than 12 test days per herd per year were available.

The following multitrait test-day animal model was assumed for the precorrected LT $\left(\mathbf{t}_{c}\right)$ :

$$
\mathbf{t}_{c}=\mathbf{X} \boldsymbol{\beta}+\mathbf{U m}+\mathbf{Z u}+\mathbf{Q p}+\mathbf{W h}+\mathbf{e},
$$

where $\boldsymbol{\beta}$ is the vector of fixed HTY effect, $\mathbf{m}$ is the vector of fixed HTM period effect, $\mathbf{u}$ is the vector of polygenic effect, $\mathbf{p}$ is the vector of permanent environment effect, $\mathbf{h}$ is the vector of random HTDr effect, $\mathbf{e}$ is the vector of the random residual, and $\mathbf{X}, \mathbf{U}, \mathbf{Z}$, $\mathbf{Q}$, and $\mathbf{W}$ are the corresponding design matrices. The following covariance structure was assumed:

$$
\operatorname{var}\left(\begin{array}{l}
\mathbf{u} \\
\mathbf{p} \\
\mathbf{h} \\
\mathbf{e}
\end{array}\right)=\left(\begin{array}{cccc}
\mathbf{G} \otimes \mathbf{A} & 0 & 0 & 0 \\
0 & \mathbf{P} \otimes \mathbf{I}_{p} & 0 & 0 \\
0 & 0 & \mathbf{H} \otimes \mathbf{I}_{h} & 0 \\
0 & 0 & 0 & \mathbf{R} \otimes \mathbf{I}_{r}
\end{array}\right),
$$

where $\mathbf{G}$ is the genetic covariance structure of LT; $\mathbf{A}$ is the numerator additive relationship matrix; $\mathbf{P}$ is the permanent environmental covariance structure of LT; $\mathbf{I}_{p}, \mathbf{I}_{h}$, and $\mathbf{I}_{r}$ are identity matrices; $\mathbf{H}$ is the HTDr covariance structure of LT; and $\mathbf{R}$ is the residual covariance structure of LT.

\section{Variance Component Estimation}

Restricted maximum likelihood (REML) estimates of (co)variance components among the M LT were obtained using the multivariate average information REML (AI-REML) algorithm of WOMBAT (Meyer, 2007). Preliminary bivariate analyses for pairs of LT were performed to get good starting values. Standard 
errors for the variance components and variance ratios were estimated from the inverse of average information matrix (Meyer, 2007) and the standard errors for the fixed effects were estimated with the additional step of the expectation maximization (EM-REML) algorithm of WOMBAT. Estimated variance components of the LT were back transformed to spectral variables using the loading matrix $(\mathbf{E})$ from Equation 1.

Variance components and heritabilities of fat, lactose, and protein percentages were estimated based on the variances obtained for LT. The method for estimating genetic parameters for milk composition traits is presented in Appendix B. Prediction equations used for estimation of heritabilities were obtained from a model calibrated on a subset of the data set used in the study.

\section{Prediction of Future $L T$}

Solutions for fixed and random effects were obtained by solving Equations 2 and 3. Predictions of future LT were done for animals in the validation data set using these solutions. The following linear model was used to compute predicted LT:

$$
\hat{\mathbf{t}}_{p}=\mathbf{X} \hat{\boldsymbol{\beta}}+\mathbf{U} \hat{\mathbf{m}}+\mathbf{Z} \tilde{\mathbf{u}}+\mathbf{Q} \tilde{\mathbf{p}}+\mathbf{C} \hat{\mathbf{f}}_{c},
$$

where $\hat{\mathbf{t}}_{p}$ is a vector of predicted LT (the subscript $p$ is used to indicate predicted LT); $\hat{\boldsymbol{\beta}}, \hat{\mathbf{m}}, \tilde{\mathbf{u}}, \tilde{\mathbf{p}}$, and $\hat{\mathbf{f}}_{c}$ are estimated or predicted solutions from Equations 2 and 3. All other model components are as explained in models 2 and 3. The design matrices $(\mathbf{X}, \mathbf{U}, \mathbf{Z}, \mathbf{Q}$, and $\mathbf{C})$ were for observation to be predicted in the validation data set. The random effect of HTDr did not appear in Equation 4, as it modeled effects specific to a herd at a given test day. For animals in the validation data set, whose breeding values are unknown, averages of their parents' breeding values were used and the permanent environmental effects were left out from the prediction equation. Correlation between predicted and observed LT was computed to evaluate the goodness of prediction of the model.

\section{RESULTS}

\section{Unprocessed FTIR Spectra}

Principal component analysis on the unprocessed spectral data resulted in 8 components (LT) that explain approximately $99 \%$ of the total spectral variation. Table 2 presents relative variance explained by the LT, estimates and standard errors of variance ratios for genetic, permanent environmental, HTDr, and random residual effects of the $8 \mathrm{LT}$. The LT are sorted according to their contribution to the total variance. The first LT explained $59 \%$ of the total spectral variation and the first 2 LT explained almost $85 \%$ of the total variation (Table 2). Genetic variance ratios (heritabilities) for these 8 LT were between 0.01 and 0.29 . Variance ratios of the permanent environmental effect were between 0.01 and 0.27 . Variance ratios for the HTDr varied from 0.02 to 0.94 and residual variance ratios ranged from 0.04 to 0.72 .

Loading plots for the $8 \mathrm{LT}$ of the unprocessed spectra are presented in Figure 2A to 2D. Latent trait 1, explaining $59 \%$ of the spectral variation, showed large contribution (loadings) for wavenumbers between 1,800 and $2,600 \mathrm{~cm}^{-1}$ (Figure 2A). This LT also had the highest residual variance ratio: 0.72 (Table 2 ). Loadings for LT 2 shows peaks in the fingerprinting region (between 1,100 and $1,450 \mathrm{~cm}^{-1}$ ) and in a region between 2,900 and $3,000 \mathrm{~cm}^{-1}$ (Figure 2A). These regions provide specific chemical information about milk composition.

Table 2. Estimates and SE of variance ratios for genetic, permanent environmental, herd test-day, and residual random effects for the unprocessed spectra ${ }^{1}$

\begin{tabular}{|c|c|c|c|c|c|}
\hline \multirow[b]{2}{*}{ Item } & \multirow[b]{2}{*}{$\begin{array}{c}\text { Percentage of } \\
\text { variance explained }\end{array}$} & \multicolumn{4}{|c|}{ Variance ratio } \\
\hline & & Genetic & $\begin{array}{c}\text { Permanent } \\
\text { environmental }\end{array}$ & Herd test day ${ }^{2}$ & Residual \\
\hline \multicolumn{6}{|l|}{ Latent trait } \\
\hline 1 & 58.96 & $0.154 \pm 0.003$ & $0.020 \pm 0.002$ & $0.105 \pm 0.005$ & $0.721 \pm 0.005$ \\
\hline 2 & 25.62 & $0.264 \pm 0.007$ & $0.091 \pm 0.005$ & $0.298 \pm 0.010$ & $0.347 \pm 0.006$ \\
\hline 3 & 7.74 & $0.146 \pm 0.004$ & $0.015 \pm 0.002$ & $0.388 \pm 0.012$ & $0.451 \pm 0.009$ \\
\hline 4 & 3.24 & $0.057 \pm 0.004$ & $0.270 \pm 0.005$ & $0.020 \pm 0.001$ & $0.653 \pm 0.004$ \\
\hline 5 & 1.66 & $0.011 \pm 0.001$ & $0.013 \pm 0.001$ & $0.941 \pm 0.003$ & $0.035 \pm 0.002$ \\
\hline 6 & 1.07 & $0.229 \pm 0.007$ & $0.135 \pm 0.006$ & $0.277 \pm 0.010$ & $0.359 \pm 0.006$ \\
\hline 7 & 0.41 & $0.211 \pm 0.006$ & $0.058 \pm 0.004$ & $0.298 \pm 0.010$ & $0.432 \pm 0.007$ \\
\hline 8 & 0.28 & $0.285 \pm 0.005$ & $0.033 \pm 0.003$ & $0.140 \pm 0.006$ & $0.542 \pm 0.005$ \\
\hline Total variance explained & 98.98 & & & & \\
\hline
\end{tabular}

${ }^{1}$ The ratios are relative to total phenotypic variance for each latent trait.

${ }^{2}$ The random effect of herd test day (HTDr). 
This LT had a moderate heritability: 0.27 (Table 2). Latent trait 3 explained $7.7 \%$ of the total variation and had a heritability of 0.15 (Table 2). The loading plot for this LT (Figure 2B) shows that it had high loadings around 1,230 and $1,771 \mathrm{~cm}^{-1}$ wavenumbers. Latent trait 4 loadings show peaks in regions 1,015 to $1,057 \mathrm{~cm}^{-1}, 1,516$ to $1,570 \mathrm{~cm}^{-1}$, and at $2,978 \mathrm{~cm}^{-1}$ (Figure 2B). The LT 5 loading showed a particularly high loading for one specific wavenumber: $2,365 \mathrm{~cm}^{-1}$ (Figure 2C). This wavenumber is related to the $\mathrm{CO}_{2}$ content of the atmosphere. This LT had the highest HTDr effect variance ratio (Table 2). The loading plot of LT 8 showed markedly higher loading at $1,725 \mathrm{~cm}^{-1}$. This wavenumber is among the strong bands associated with $\mathrm{C}=\mathrm{O}$ stretch vibration from lipids. The LT also had high loadings in the fingerprinting region (between 1,000 and $1,300 \mathrm{~cm}^{-1}$ ) and $2,978 \mathrm{~cm}^{-1}$ (Figure 2D). This component has the highest heritability among LT: 0.28 (Table 2).

Estimated variance components of LT were back transformed to the spectral variables using the loading matrix $\mathbf{E}$ from Equation 1. Figure 3 presents estimated variance ratios of the spectral variables for genetic and permanent environmental effects. Variance ratios of the spectral variables were between 0.02 and 0.41 for genetic and between 0 and 0.18 for permanent environmental effects (Figure 3). High to moderate heritabilities were observed in regions between 1,100 and 1,350 $\mathrm{cm}^{-1}$, between 1,700 and $1,770 \mathrm{~cm}^{-1}$, and between 2,800 and $3,000 \mathrm{~cm}^{-1}$ (Figure 3, solid line). Higher permanent environmental variance ratios were observed in regions between 1,100 and 1,150 $\mathrm{cm}^{-1}$, and between 1,500 and $1,597 \mathrm{~cm}^{-1}$ (Figure 3, dotted line).

Repeatabilities of the spectral variables were computed as a sum of genetic and permanent environmental variance. The repeatabilities are plotted along with HTDr effects on the same figure (Figure 4) to show regions of the spectra influenced by individual variability and HTD variability. Variance ratios of spectral variables for HTDr effect ranged from 0.01 to 0.69 and from 0.07 to 0.49 for repeatability. Figure 4 shows that higher repeatability values were observed in the fingerprinting region of the spectra (between 1,100 and 1,500 $\mathrm{cm}^{-1}$ ) and in the region between 2,800 and $3,000 \mathrm{~cm}^{-1}$
(A)

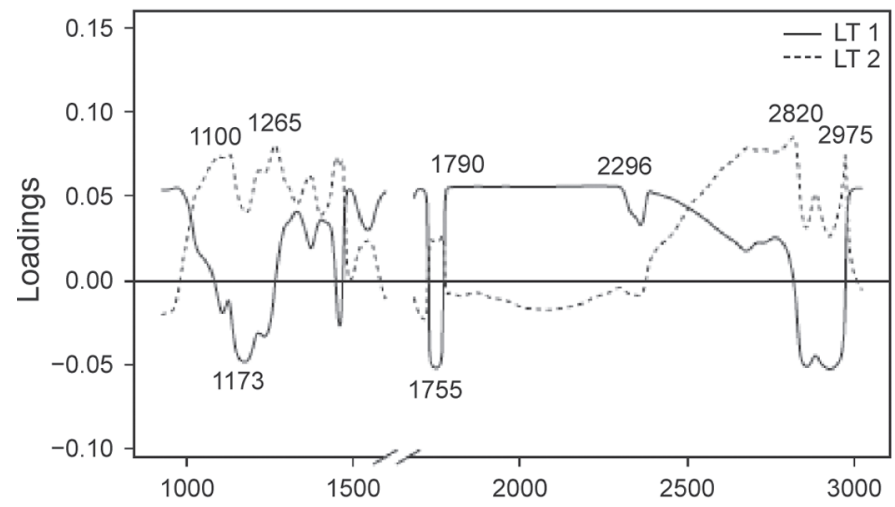

(C)

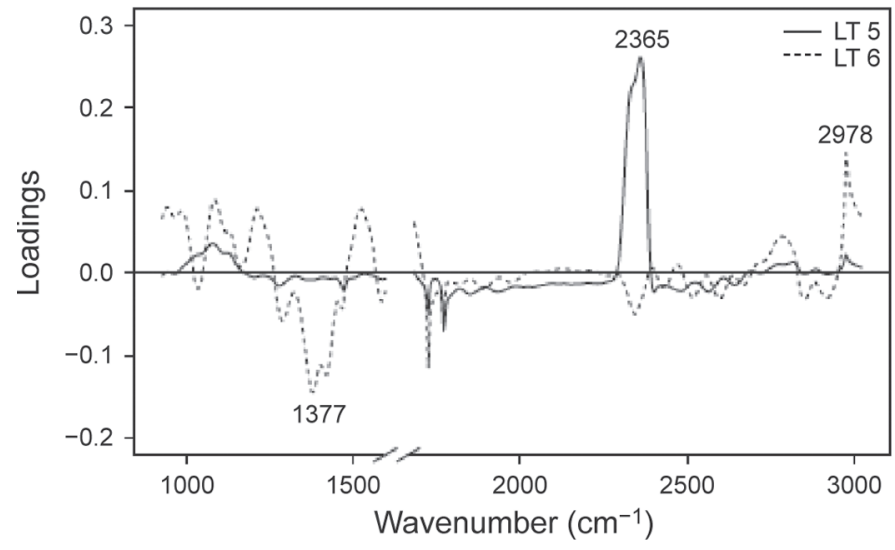

(B)

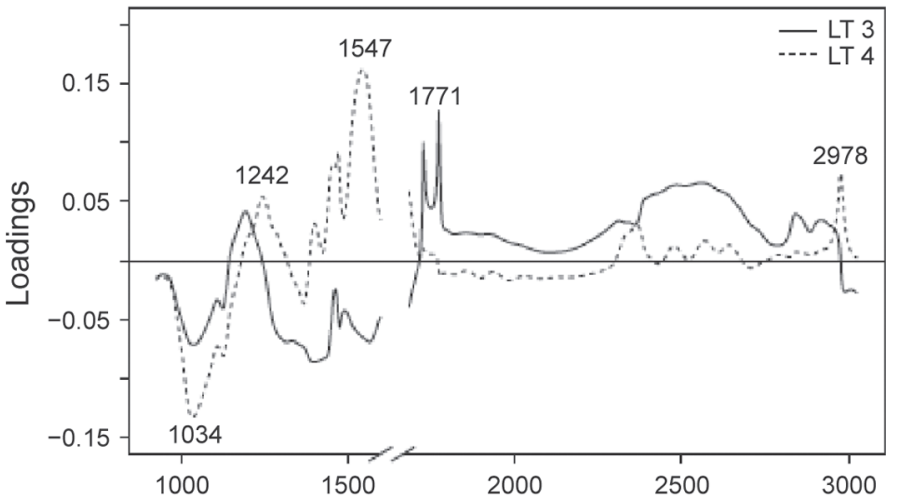

(D)

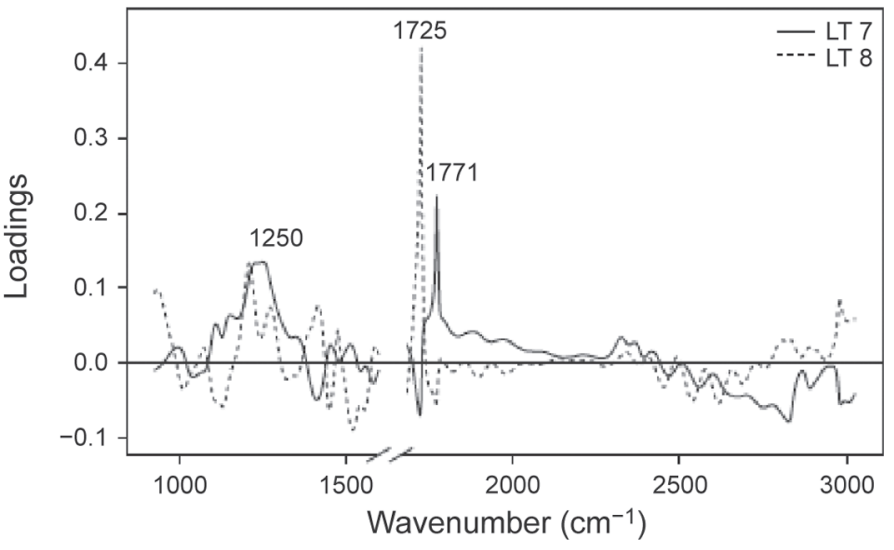

Figure 2. Loading plots for the unprocessed spectra principal components (latent traits, LT). (A) Loading plots of LT 1 and LT 2 . (B) Loading plots of LT 3 and LT 4. (C) Loading plots of LT 5 and LT 6. (D) Loading plots of LT 7 and LT 8. 


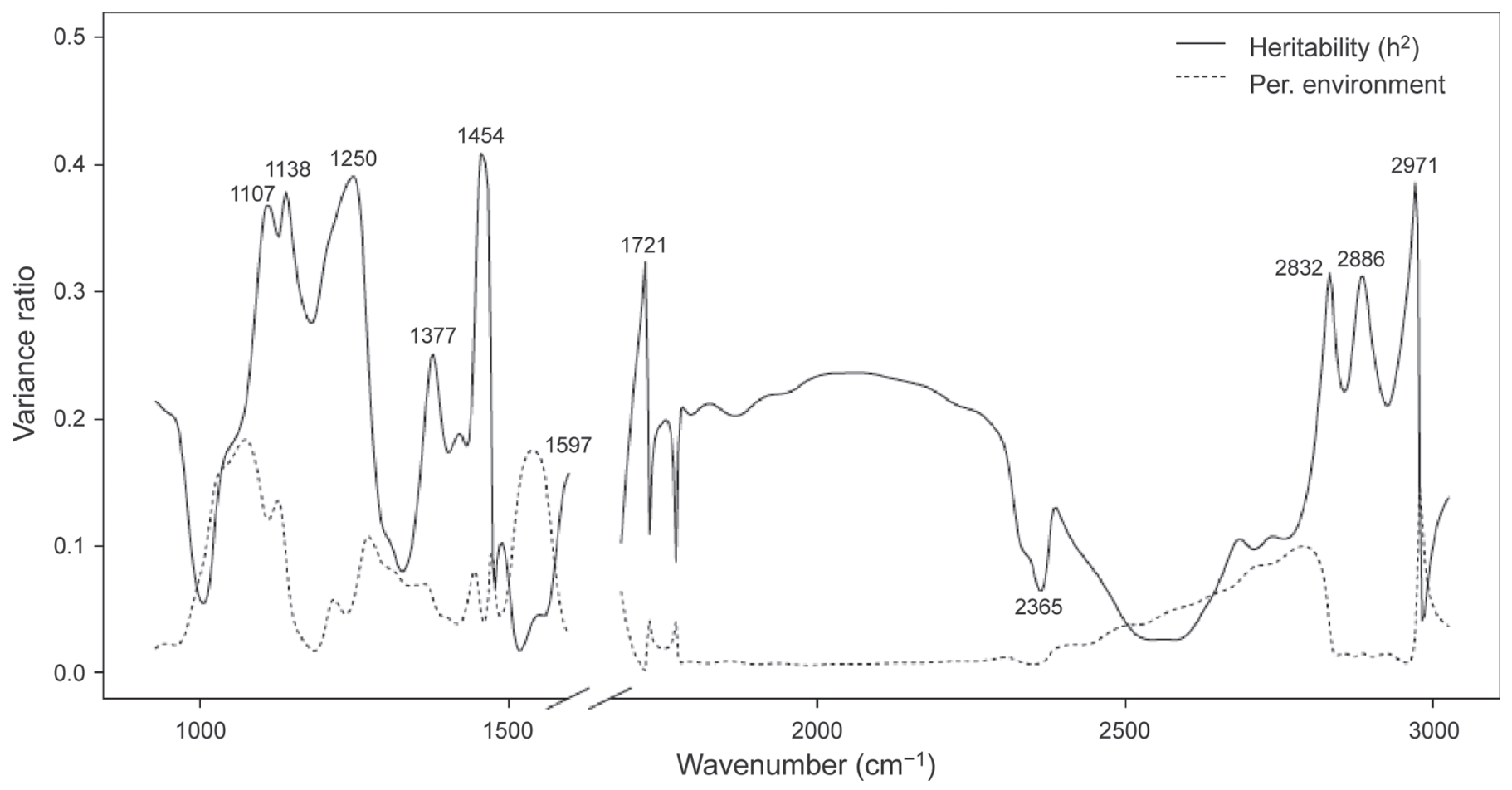

Figure 3. Additive genetic (solid line) and permanent environmental (dotted line) variance ratios of back transformed goat milk Fourier transform infrared (FTIR) spectral variables. The variance ratios are calculated as the respective variances divided by total phenotypic variation. Approximate standard errors ranged from 0.002 to 0.035 for the genetic variance ratios and from 0.003 to 0.036 for the permanent environmental (Per. environment) variance ratios.

(Figure 4, dotted line). The spectral region between 2,300 and $2,800 \mathrm{~cm}^{-1}$ is highly dominated by HTDr variation (Figure 4, solid line).

\section{EMSC Preprocessed FTIR Spectra}

The PCA on the EMSC preprocessed spectra (i.e., 262 spectral data points) resulted in 7 components (LT) explaining more than $99 \%$ of the total spectral variation. Table 3 presents relative variance explained by the LT, and estimates and standard errors of variance ratios for genetic, permanent environmental, HTDr, and random residual effects of the $7 \mathrm{LT}$, and the EMSC multiplicative parameter (b). Genetic variance ratios (heritabilities) for the $7 \mathrm{LT}$ were between 0.14 and 0.26 . Variance ratios of the permanent environmental effect were between 0.09 and 0.19 . Variance ratios of the HTDr effect for the LT varied from 0.19 to 0.42 and residual variance ratios ranged from 0.28 to 0.43 . The variance ratios for the multiplicative parameter $b$ were 0.19 for genetic, 0.15 for permanent environmental, 0.27 for HTDr, and 0.39 for random residual effects (Table 3).

Loading plots for the 7 LT of the preprocessed spectra are presented in Figure 5A to 5D. Latent trait 1 of the preprocessed spectra explained $72 \%$ of the variation in the data set and had a heritability of 0.14 (Table 3). The LT 1 loadings plot (Figure 5A, solid line) showed large contribution from several wavenumbers $(1,076$, $1,181,1,555,1,740,2,855$, and $\left.2,924 \mathrm{~cm}^{-1}\right)$. Latent trait 2 , explaining $13 \%$ of the variation, had the highest heritability among the LT: 0.26 (Table 3). The LT 2 loadings (Figure 5A, dotted line) seemed to have large contribution at $1,038 \mathrm{~cm}^{-1}$ (within the lactose region), $1,547 \mathrm{~cm}^{-1}$ (within the amide II region), and $2,924 \mathrm{~cm}^{-1}$ (within the milk lipid region). The third component (LT 3 ), which explained $6.6 \%$ of sample variation (Table 3 ), had high loadings at $1,134 \mathrm{~cm}^{-1}$ (from a mixture of fat, lactose, and protein), at $1,084 \mathrm{~cm}^{-1}$ (from lactose), and at $1,412,1,524,1,588,1,744$, and $2,924 \mathrm{~cm}^{-1}$ from a combination of milk fat and protein (Figure 5B, solid line). Latent trait 4 loading showed peaks at $1,076 \mathrm{~cm}^{-1}$ from lactose, and 1,713 and $1,744 \mathrm{~cm}^{-1}$ from milk lipids (Figure 5B, dotted line). For LT 5, dominant loading peaks were observed at 1,030, 1,089, 1,594, 1,740, and $2,927 \mathrm{~cm}^{-1}$ (Figure 5C, solid line). These wavenumbers are related to major milk components. Loadings of LT 6 (Figure 5C, dotted line) showed peaks at 1,728, 1,767, $2,843,2,909$, and $2,932 \mathrm{~cm}^{-1}$ (all these wavelength numbers are related to milk fat). 
Table 3. Estimates and SE of variance ratios for genetic, permanent environmental, herd test-day, and residual random effects for the extended multiplicative signal correction (EMSC)-treated spectra ${ }^{1}$

\begin{tabular}{|c|c|c|c|c|c|}
\hline \multirow[b]{2}{*}{ Item } & \multirow[b]{2}{*}{$\begin{array}{c}\text { Percentage of } \\
\text { variance explained }\end{array}$} & \multicolumn{4}{|c|}{ Variance ratio } \\
\hline & & Genetic & $\begin{array}{c}\text { Permanent } \\
\text { environmental }\end{array}$ & Herd test day ${ }^{2}$ & Residual \\
\hline \multicolumn{6}{|l|}{ Latent trait } \\
\hline 1 & 72.43 & $0.135 \pm 0.012$ & $0.133 \pm 0.013$ & $0.304 \pm 0.011$ & $0.428 \pm 0.010$ \\
\hline 2 & 13.39 & $0.262 \pm 0.015$ & $0.189 \pm 0.015$ & $0.185 \pm 0.009$ & $0.364 \pm 0.007$ \\
\hline 3 & 6.57 & $0.254 \pm 0.014$ & $0.130 \pm 0.013$ & $0.277 \pm 0.011$ & $0.339 \pm 0.008$ \\
\hline 4 & 2.89 & $0.185 \pm 0.012$ & $0.160 \pm 0.012$ & $0.377 \pm 0.012$ & $0.278 \pm 0.007$ \\
\hline 5 & 1.76 & $0.207 \pm 0.013$ & $0.110 \pm 0.013$ & $0.369 \pm 0.011$ & $0.363 \pm 0.009$ \\
\hline 6 & 1.23 & $0.156 \pm 0.011$ & $0.091 \pm 0.010$ & $0.416 \pm 0.012$ & $0.337 \pm 0.009$ \\
\hline 7 & 0.85 & $0.216 \pm 0.013$ & $0.108 \pm 0.012$ & $0.317 \pm 0.011$ & $0.359 \pm 0.008$ \\
\hline $\mathrm{b}$ & - & $0.191 \pm 0.013$ & $0.150 \pm 0.013$ & $0.273 \pm 0.011$ & $0.385 \pm 0.009$ \\
\hline Total variance explained & 99.12 & & & & \\
\hline
\end{tabular}

${ }^{1}$ The ratios are relative to total phenotypic variance for each latent trait and the multiplicative parameter $\mathrm{b}$.

${ }^{2}$ The random effect of herd test day (HTDr).

\section{Prediction of Future $L T$}

Latent traits were predicted for animals in the validation data set for both unprocessed and EMSC preprocessed FTIR spectral data using Equation 4. These predicted LT were then compared with observed LT in the validation data set. Correlations between predicted and observed LT are presented in Table 4 . The table shows that the correlations were between 0.42 and 0.73 in the untreated spectral data and between 0.48 and 0.74 in the preprocessed spectral data.

\section{DISCUSSION}

The remarkable reduction in the number of components needed to capture a large proportion of spectral variation (i.e., only 8 components were enough to capture approximately $99 \%$ of total spectral variation)

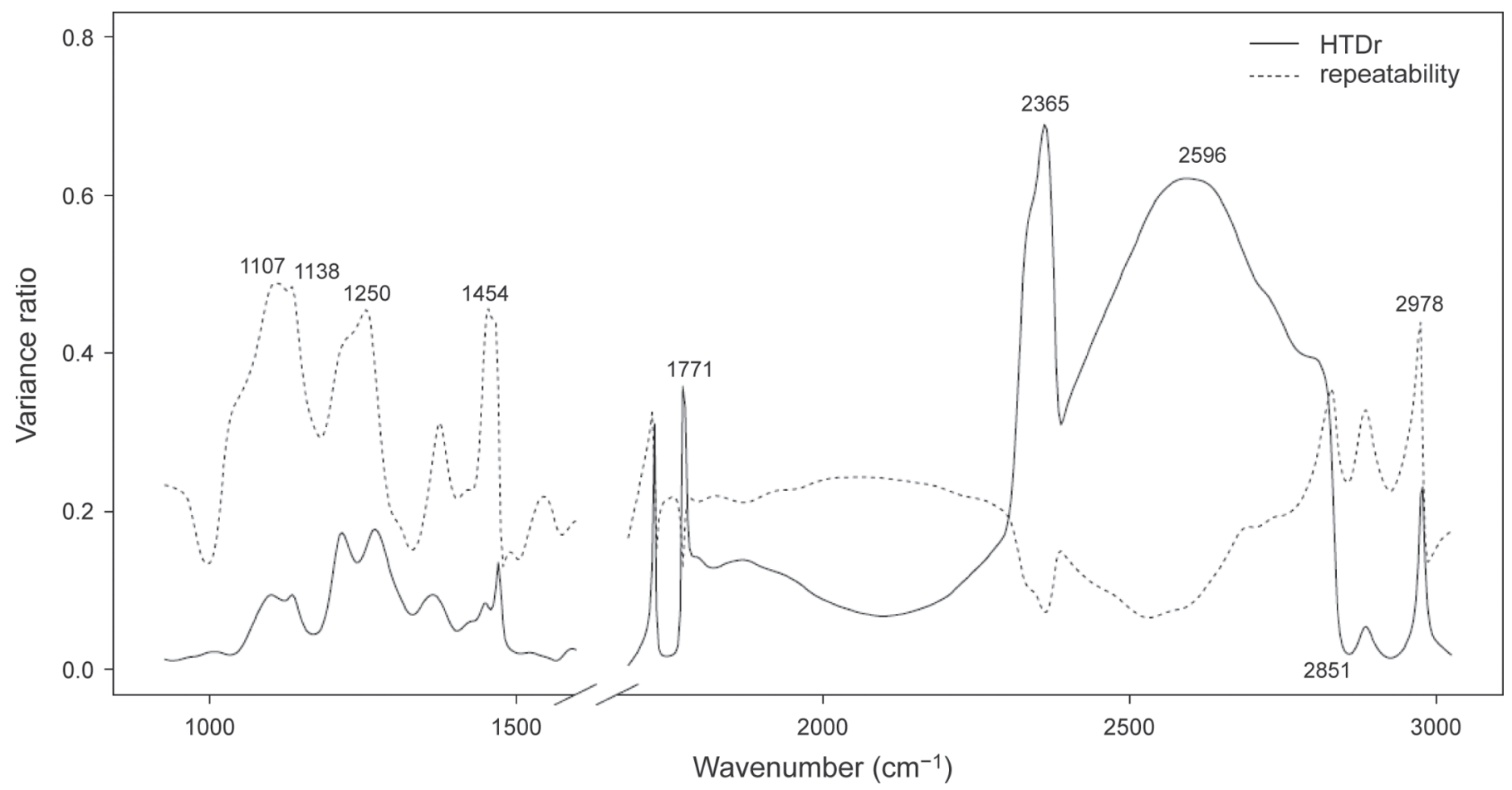

Figure 4. Variance ratios of random effect of herd test day (HTDr; solid line) and repeatability (dotted line). The variance ratios are calculated as the respective variances divided by total phenotypic variation. Approximate standard errors for HTDr variance ratios varied between 0.001 and 0.077 
Table 4. Correlation between predicted and observed latent traits for the unprocessed and preprocessed milk Fourier transform infrared (FTIR) spectra

\begin{tabular}{lcc}
\hline Latent trait & $\begin{array}{c}\text { Untreated FTIR } \\
\text { validation }\end{array}$ & $\begin{array}{c}\text { Preprocessed } \\
\text { FTIR validation }\end{array}$ \\
\hline 1 & $0.557 \pm 0.009$ & $0.534 \pm 0.010$ \\
2 & $0.696 \pm 0.007$ & $0.747 \pm 0.007$ \\
3 & $0.574 \pm 0.009$ & $0.625 \pm 0.009$ \\
4 & $0.706 \pm 0.008$ & $0.653 \pm 0.008$ \\
5 & $0.422 \pm 0.010$ & $0.599 \pm 0.009$ \\
6 & $0.735 \pm 0.007$ & $0.484 \pm 0.010$ \\
7 & $0.529 \pm 0.009$ & $0.633 \pm 0.009$ \\
8 & $0.500 \pm 0.011$ & \\
$\mathrm{~b}^{1}$ & & $0.311 \pm 0.011$ \\
\hline
\end{tabular}

${ }^{1}$ The extended multiplicative signal correction (EMSC) multiplicative parameter.

for both unprocessed and EMSC preprocessed spectra indicates that individual spectral variables are strongly correlated. For the unprocessed spectra, the first component explained almost $60 \%$ of the total spectral variation (Table 2 ). The higher residual variance ratio observed for this component (0.72; Table 2) can be explained by its higher loadings for wavelength numbers between 1,800 and 2,600 $\mathrm{cm}^{-1}$ (Figure 2A, solid line). This spectral region had limited chemical information and has no specific peaks in a raw FTIR spectrum (Figure 1A; Andersen et al., 2002; Iñón et al., 2004) and might have contributed to the higher noise.

The rank of the LT according to their relative eigenvalues did not agree with their importance according to their heritabilities for untreated or preprocessed spectra (Tables 2 and 3), implying that the largest variation of the spectral data was not genetically determined. For instance, for the untreated spectral data, LT 8 had the highest heritability but the lowest relative eigenvalue among the LT (Table 2) and similar observations could be made for the preprocessed spectra (Table 3 ).

All implications of the observed genetic variability of individual wavenumbers are difficult to comprehend because milk IR spectra represent several different kinds of biomolecules of the milk (Soyeurt et al., 2010). However, genetic variability of some regions of the FTIR spectra could be interpreted from previous understanding of the spectra. The fingerprint region of the spectra, between 900 and $1,500 \mathrm{~cm}^{-1}$, is associated with $\mathrm{C}-\mathrm{O}$
(A)

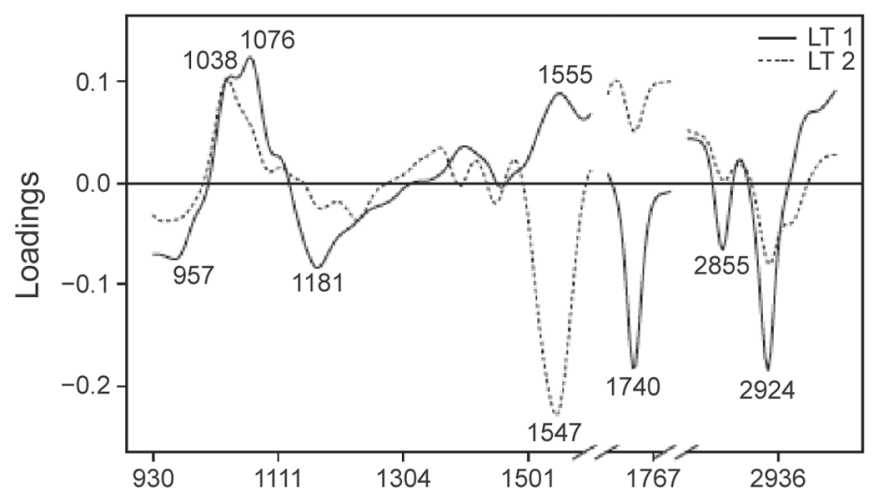

(C)

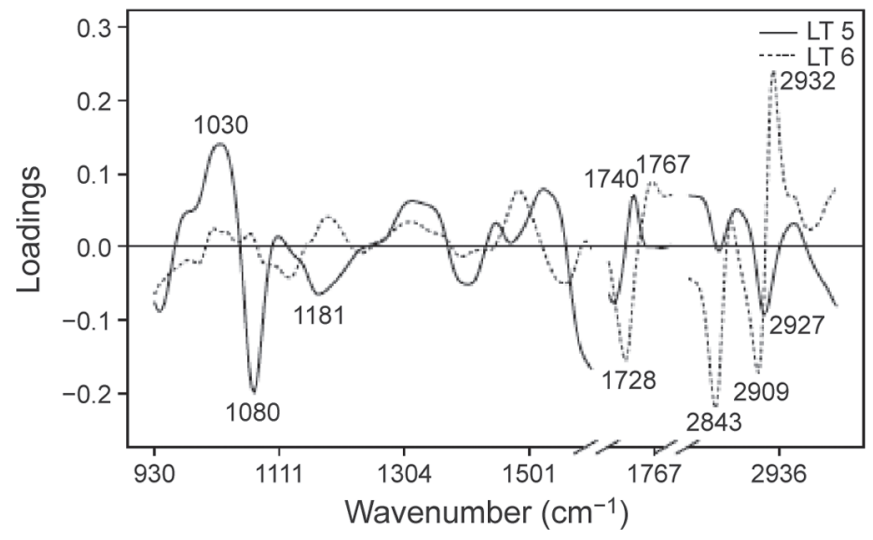

(B)

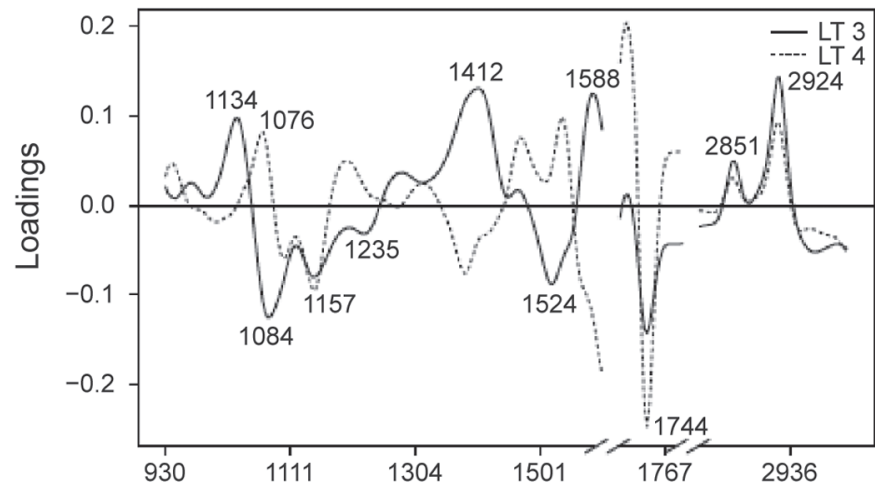

(D)

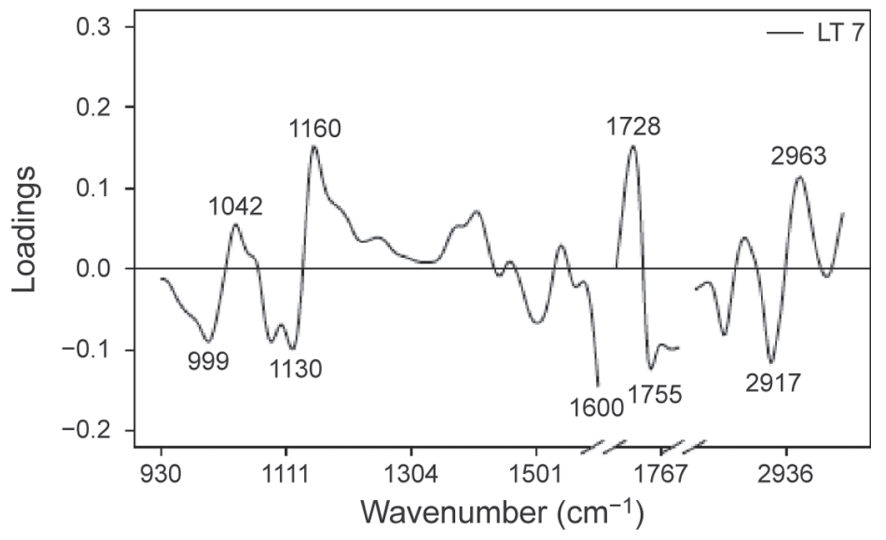

Figure 5. Loading plots for the extended multiplicative signal correction (EMSC) preprocessed spectra principal components (latent traits, LT). (A) Loading plots of LT 1 and LT 2. (B) Loading plots of LT 3 and LT 4. (C) Loading plots of LT 5 and LT 6. (D) Loading plot of LT 7. 
and $\mathrm{C}-\mathrm{C}$ stretching; $\mathrm{OH}, \mathrm{CH}$, and $\mathrm{CHH}$ deformation; $\mathrm{CH}$ rock and $\mathrm{CH}_{2}$ wagging molecular vibration modes (Socrates, 2001; Iñón et al., 2004; Kohler et al., 2010). In milk, these molecular functional groups are common due to the major milk components such as carbohydrates, lipids, protein, and a mixture of 2 or more of these individual components. The genetic variability peaks in this region (Figure 3) observed in the present study could be related to the genetic variability of these major milk components.

Lactose is expected to have absorption peak in IR region between 1,030 and $1,150 \mathrm{~cm}^{-1}$ due to the presence of the hydroxyl (OH) group (Lei et al., 2010). Figure 3 shows genetic variance ratio peaks in spectral regions between 1,010 and $1,180 \mathrm{~cm}^{-1}$ and these peaks could be related to lactose content of milk. Milk protein is expected to have absorption bands around 1,650, 1,550 , and $1,250 \mathrm{~cm}^{-1}$ due to amide I, amide II, and amide III groups, respectively (Hewavitharana and van Brakel, 1997). It also has an absorbance peak in the region between 1,060 and $1,100 \mathrm{~cm}^{-1}$, associated with a phosphate group bound to casein protein (Etzion et al., 2004). The amide I band peak, which would appear at $1,650 \mathrm{~cm}^{-1}$ due to $\mathrm{C}=\mathrm{O}$ stretching (Hewavitharana and van Brakel, 1997), was removed from this analysis due to water absorption. Band information related to milk protein (amide I) could be lost and could have improved spectral genetic variability. Afseth et al. (2010) suggested the use of dried film measurements to retain this information. Amide III of milk protein has an absorption peak around $1,250 \mathrm{~cm}^{-1}$ mainly due to C-N stretching (Lei et al., 2010) and Figure 3 shows a heritability peak at the $1,250 \mathrm{~cm}^{-1}$ position.

Determination of fat content of milk samples from FTIR spectra is mainly based on 2 specific regions. The spectral region between 1,720 and $1,760 \mathrm{~cm}^{-1}$ has strong absorption bands due to the carbonyl $(\mathrm{C}=\mathrm{O})$ group of milk lipids (commonly referred to as fat A). Another spectral region located between 2,800 and $3,000 \mathrm{~cm}^{-1}$ absorbs IR light due to the alkyl chain of FA (commonly referred to as fat B; Andersen et al., 2002; Iñón et al., 2004). The genetic variance ratio peaks observed in Figure 3 around these regions - between 1,700 and $1,800 \mathrm{~cm}^{-1}$, and 2,800 and $3,000 \mathrm{~cm}^{-1}$ - could be related to genetic variability of milk fat.

The spectral region between 1,800 and $2,800 \mathrm{~cm}^{-1}$ does not provide any known relevant chemical information about milk samples (Andersen et al., 2002; Iñón et al., 2004) and had no specific band present in the raw FTIR spectrum (Figure 1A). The higher HTDr variance ratios in this spectral region (Figure 4) suggest that the region is highly influenced by laboratory environment specific to a test-day or internal parameter of the FTIR instrument, or a combination of both. The very distinct peak variance ratio of HTDr around 2,360 $\mathrm{cm}^{-1}$ (Figure 4) is related to atmospheric $\mathrm{CO}_{2}$ (Iñón et al., 2004), which is highly determined by laboratory atmosphere of a test day.

Heritabilities and other genetic parameters of milk composition traits can be estimated from the genetic variance component of milk FTIR spectra. For instance, heritabilities of major milk components (i.e., fat, lactose, and protein) estimated from genetic variance component of the spectra were 0.26 for fat, 0.33 for lactose, and 0.32 for protein percentages based on the found variance components of the spectra. These estimated parameters could be compared with estimated heritabilities of major milk components in the genetic evaluation program. Fat, lactose and protein percentages have heritabilities of $0.27,0.38$, and 0.35 , respectively, in the Norwegian goat population [Norwegian Sheep and Goat Breeders' Association (NSG), Ås, Norway; I. A. Boman, personal communication, 2009]. The heritabilities found based on our data set are slightly lower that theses, but estimates are based on different data sets.

One of several advantages of using test-day models instead of 305-d lactation models is that individual test-day effects can be included in the model and environmental effects peculiar to each test day can be accounted for (Ptak and Schaeffer, 1993). This provides the possibility of using the HTD effect solutions as a continuous herd management monitoring tool, as the effect can be thought of as an effect that considers management practices and other environmental conditions that are likely to vary from test day to test day in a herd (Van Bebber et al., 1999).

The present study showed that some of the latent traits could be predicted with reasonable accuracy (Table 4). This information could be used as a herd management monitoring tool to detect variation in milk composition due to changes in some management aspect specific to a herd, such as feeding practice. The raw FTIR spectra used for prediction of milk composition phenotypes could also be used to observe LT. These values could be compared with predicted LT $\left(\hat{\mathbf{t}}_{p}\right)$. Any suspect variations from the usual pattern may assist in identifying specific problems related to a test day in a herd. When a problem is identified, it can be related to individual physiology, herd feeding practice, and so on. Mayeres et al. (2002) implemented test-day model solutions as a herd-monitoring tool using predicted milk composition and milk yield phenotypes. Here, we proposed the use of milk FTIR spectra instead because information is richer than the few predicted phenotypes, and expected to be more sensitive to 
changes in milk composition. However, use of the information for herd management purposes needs to be elaborated further.

Finally we point out that the approach presented in the current study is a 2 -step procedure (i.e., first PCA was applied to distill the milk FTIR spectral variables into a few LT and then genetic parameters were estimated for these LT). The procedure might not be efficient to extract such information, as pointed out by Kirkpatrick and Meyer (2004). The ideal situation would be to extract genetic principal components directly without the intermediate dimension reduction step (i.e., PCA) as described in Kirkpatrick and Meyer (2004). With the current available methods in quantitative genetics, however, it was not possible to deal with all spectral traits simultaneously.

\section{CONCLUSIONS}

The study presents the genetic and environmental variability of goat milk FTIR spectra. The genetic variability of the spectra was as expected, knowing the genetic parameters of major milk components and their relation to spectral variables. The study demonstrated that some regions of the spectra are highly to moderately influenced by additive genetic effect, whereas some other spectral regions are controlled by temporary as well as permanent environmental factors. The study also pointed out the possibility of using FTIR spectra as a tool in herd management.

\section{ACKNOWLEDGMENTS}

This study was financially supported by the Research Council of Norway (Oslo), TINE SA (Oslo; Norwegian dairies), and the Norwegian University of Life Sciences (Ås, Norway). The authors gratefully acknowledge TINE for providing milk FTIR spectral data free of charge.

\section{REFERENCES}

Afseth, N. K., H. Martens, Å. Randby, L. Gidskehaug, B. Narum, K. Jørgensen, S. Lien, and A. Kohler. 2010. Predicting the fatty acid composition of milk: A comparison of two Fourier transform infrared sampling techniques. Appl. Spectrosc. 64:700-707.

Ali, T. E., and L. Schaeffer. 1987. Accounting for covariances among test day milk yields in dairy cows. Can. J. Anim. Sci. 67:637-644.

Andersen, S. K., P. W. Hansen, and H. V. Andersen. 2002. Vibrational spectroscopy in the analysis of dairy products and wine. Pages 3672-3681 in Handbook of Vibrational Spectroscopy. J. M. Chalmers and P. R. Griffiths, ed. John Wiley \& Sons Ltd., West Sussex, UK.

Etzion, Y., R. Linker, U. Cogan, and I. Shmulevich. 2004. Determination of protein concentration in raw milk by mid-infrared Fourier transform infrared/attenuated total reflectance spectroscopy. J. Dairy Sci. 87:2779-2788.
Everett, R. W., F. Schmidt, and L. H. Wadell. 1994. A test day model for monitoring management and genetics in dairy cattle. J. Dairy Sci. 77(Suppl. 1):267. (Abstr.)

Goulden, J. D. S. 1964. Analysis of milk by infra-red absorption. J. Dairy Res. 31:273-284. http://dx.doi.org/10.1017/ S0022029900018203.

Hansen, P. W., A. S. Van Brakel, J. Garman, and L. Nørgaard. 1999. Detection of specific sugars in dairy process samples using multivariate curve resolution. J. Dairy Sci. 82:1351-1360.

Hewavitharana, A. K., and B. van Brakel. 1997. Fourier transform infrared spectrometric method for the rapid determination of casein in raw milk. Analyst (Lond.) 122:701-704.

Iñón, F. A., S. Garrigues, and M. de la Guardia. 2004. Nutritional parameters of commercially available milk samples by FTIR and chemometric techniques. Anal. Chim. Acta 513:401-412.

Kirkpatrick, M., and K. Meyer. 2004. Direct estimation of genetic principal components: Simplified analysis of complex phenotypes. Genetics 168:2295-2306.

Kohler, A., N. K. Afseth, K. Jørgensen, Å. Randby, and H. Martens. 2010. Quality analysis of milk by vibrational spectroscopy. Pages 483-499 in Applications of Vibrational Spectroscopy in Food Sciences. Vol. 2. E. Li-Chan, P. R. Griffiths and J. M. Chalmers, ed. John Wiley \& Son, Ltd., West Sussex, UK.

Kohler, A., M. Zimonja, V. Segtnan, and H. Martens. 2009. Standard normal variate, multiplicative signal correction and extended multiplicative signal correction preprocessing in biospectroscopy. Pages 139-162 in Comprehensive Chemometrics: Chemical and Biochemical Data Analysis. S. D. Brown, R. Tauler and R. Walczak, ed. Elsevier, Oxford, UK.

Lei, Y., Q. Zhou, Y. Zhang, J. Chen, S. Sun, and I. Noda. 2010. Analysis of crystallized lactose in milk powder by Fourier-transform infrared spectroscopy combined with two-dimensional correlation infrared spectroscopy. J. Mol. Struct. 974:88-93.

Luinge, H. J., E. Hop, E. T. G. Lutz, J. A. van Hemert, and E. A. M. de Jong. 1993. Determination of the fat, protein and lactose content of milk using Fourier transform infrared spectrometry. Anal. Chim. Acta 284:419-433.

Martens, H., and T. Næs. 1989. Multivariate Calibration. John Wiley \& Sons Ltd., West Sussex, UK.

Mayeres, P., J. Stoll, R. Reents, and N. Gengler. 2002. Alternative modeling of fixed effects in test day models to increase their usefulness for management decisions. Interbull Bull. 29:128-132.

Meyer, K. 2007. Wombat-A tool for mixed model analyses in quantitative genetics by REML. J. Zhejiang Univ. Sci. B 8:815-821. http://dx.doi.org/10.1631/jzus.2007.B0815.

Nicolaou, N., Y. Xu, and R. Goodacre. 2010. Fourier transform infrared spectroscopy and multivariate analysis for the detection and quantification of different milk species. J. Dairy Sci. 93:56515660.

Nieuwoudt, H. H., B. A. Prior, I. S. Pretorius, M. Manley, and F. F. Bauer. 2004. Principal component analysis applied to Fourier transform infrared spectroscopy for the design of calibration set for glycerol prediction models in wine and for the detection and classification of outlier samples. J. Agric. Food Chem. 52:3726-3735.

Ptak, E., and L. R. Schaeffer. 1993. Use of test day yields for genetic evaluation of dairy sires and cows. Livest. Prod. Sci. 34:23-34.

Rodriguez-Saona, L. E., N. Koca, W. J. Harper, and V. B. Alvarez. 2006. Rapid determination of Swiss cheese composition by Fourier transform infrared/attenuated total reflectance spectroscopy. J. Dairy Sci. 89:1407-1412.

Rutten, M. J. M., H. Bovenhuis, J. M. L. Heck, and J. A. M. van Arendonk. 2011. Predicting bovine milk protein composition based on Fourier transform infrared spectra. J. Dairy Sci. 94:5683-5690. http://dx.doi.org/10.3168/jds.2011-4520.

SAS Institute. 2004. SAS/STAT User's Guide. SAS Institute Inc., Cary, NC.

Socrates, G. 2001. Infrared and Raman Characteristic Group Frequencies. John Wiley \& Sons Ltd., Chichester, UK.

Soyeurt, H., P. Dardenne, F. Dehareng, G. Lognay, D. Veselko, M. Marlier, C. Bertozzi, P. Mayeres, and N. Gengler. 2006. Estimating 
fatty acid content in cow milk using mid-infrared spectrometry. J. Dairy Sci. 89:3690-3695.

Soyeurt, H., I. Misztal, and N. Gengler. 2010. Genetic variability of milk components based on mid-infrared spectral data. J. Dairy Sci. 93:1722-1728.

Van Bebber, J., N. Reinsch, W. Junge, and E. Kalm. 1999. Monitoring daily milk yields with a recursive test day repeatability model (Kalman filter). J. Dairy Sci. 82:2421-2429.

van de Voort, F. R. 1992. Fourier transform infrared spectroscopy applied to food analysis. Food Res. Int. 25:397-403.

\section{APPENDIX A}

\section{Estimation of FTIR Spectra Variance Components}

A principal component decomposition of milk FTIR spectra can be represented as follows:

$$
\mathbf{Y}_{(\mathrm{N} \times \mathrm{K})}=\mathbf{T}_{(\mathrm{N} \times \mathrm{M})} \mathbf{E}_{(\mathrm{M} \times \mathrm{K})}^{\prime}+\mathbf{F}_{(\mathrm{N} \times \mathrm{K})},
$$

where $\mathbf{Y}_{(\mathrm{N} \times \mathrm{K})}$ is the FTIR spectral data matrix (with $\mathrm{N}$ rows representing milk samples and $\mathrm{K}$ columns representing results for the different wavelengths), $\mathrm{N}$ is the number of observations, $\mathrm{K}$ is the number of wavelengths, $\mathbf{T}_{(\mathrm{N} \times \mathrm{M})}$ is the matrix of the samples' scores for the M latent variables, $\mathrm{M}$ is the number of components extracted $(\mathrm{M} \leq \mathrm{K}), \mathbf{E}_{(\mathrm{M} \times \mathrm{K})}^{\prime}$ is the loading matrix linking latent variables to spectral variables and $\mathbf{F}_{(\mathrm{N} \times \mathrm{K})}$ is the unmodeled residual.

Equation A1 can also be written in vector form as follows:

$$
\mathbf{y}=\left(\mathbf{I}_{\mathrm{N}} \otimes \mathbf{E}\right) \cdot \mathbf{t}+\mathbf{f}
$$

$$
\left[\begin{array}{c}
\mathbf{y}_{11} \\
\mathbf{y}_{12} \\
\vdots \\
\mathbf{y}_{1 \mathrm{~K}} \\
\vdots \\
\mathbf{y}_{\mathrm{NK}}
\end{array}\right]=\left[\begin{array}{llll}
\mathbf{E} & & & \\
& \mathbf{E} & & \\
& & \ddots & \\
& & & \mathbf{E}
\end{array}\right] \cdot\left[\begin{array}{c}
\mathbf{t}_{11} \\
\mathbf{t}_{12} \\
\vdots \\
\mathbf{t}_{1 \mathrm{M}} \\
\vdots \\
\mathbf{t}_{\mathrm{NM}}
\end{array}\right]+\left[\begin{array}{c}
\mathbf{f}_{11} \\
\mathbf{f}_{12} \\
\vdots \\
\mathbf{f}_{1 \mathrm{~K}} \\
\vdots \\
\mathbf{f}_{\mathrm{NK}}
\end{array}\right],
$$

where $\mathbf{y}$ is a vector of spectral variables (with the spectra of one sample on top of the other), $\mathbf{t}$ is a vector of scores (with the scores of one sample on top of the other), $\mathbf{E}$ is a matrix of loading, $\mathbf{I}_{\mathrm{N}}$ is an identity matrix of $\mathrm{N}$ dimension, $\boldsymbol{\otimes}$ is a Kronecker multiplication, and $\mathbf{f}$ is a vector of residuals (with the residual of one sample on top of the other).

Assume the following multitrait test-day model to find variance components for the LT:

$$
\mathbf{t}=\mathbf{X} \boldsymbol{\beta}+\mathbf{Z u}+\mathbf{Q p}+\mathbf{W h}+\mathbf{e},
$$

where $\boldsymbol{\beta}$ is a vector of fixed effects of the $\mathrm{LT}, \mathbf{u}$ is a vector of additive genetic effect, $\mathbf{p}$ is a vector of permanent environmental effect, $\mathbf{h}$ is a vector of HTDr, $\mathbf{e}$ is a vector of the random residual, and $\mathbf{X}, \mathbf{U}, \mathbf{Z}, \mathbf{Q}$, and $\mathbf{W}$ are the corresponding design matrices. Assume var $(\mathbf{u})=$ $\mathbf{G}_{t} \otimes \mathbf{A}, \operatorname{var}(\mathbf{p})=\mathbf{P}_{t} \otimes \mathbf{I}_{p}, \operatorname{var}(\mathbf{h})=\mathbf{H}_{t} \otimes \mathbf{I}_{h}$, and var $(\mathbf{e})=\mathbf{R}_{t} \otimes \mathbf{I}_{N}$, where $\mathbf{G}_{t}$ is the genetic covariance structure of the LT, $\mathbf{A}$ is the numerator additive relationship matrix, $\mathbf{P}_{t}$ is the permanent environmental covariance structure of the LT, $\mathbf{H}_{t}$ is the HTDr covariance structure of the LT, $\mathbf{R}_{t}$ is the residual covariance structure of the LT, and $\mathbf{I}_{p}, \mathbf{I}_{h}$, and $\mathbf{I}_{\mathrm{N}}$ are identity matrices.

With information on additive relationship (A) of individuals in the data set, estimates of the variance components may be found using REML:

$L\left(\mathbf{G}_{t}, \mathbf{P}_{t}, \mathbf{H}_{t}, \mathbf{R}_{t} \mid \mathbf{t}, \mathbf{A}\right) \stackrel{\text { yields }}{\longrightarrow} \hat{\mathbf{G}}_{t}, \hat{\mathbf{P}}_{t}, \hat{\mathbf{H}}_{t}$, and $\hat{\mathbf{R}}_{t}$,

where $\hat{\mathbf{G}}_{t}, \hat{\mathbf{P}}_{t}, \hat{\mathbf{H}}_{t}$, and $\hat{\mathbf{R}}_{t}$ are REML estimates of the genetic, permanent environmental, HTDr, and residual variance components of the LT, respectively.

The estimated variance components of the LT (from Equation A4) can then be used to find variance components of the FTIR spectra (through back transformation):

$$
\hat{\mathbf{G}}_{y}=\mathbf{E} \cdot \hat{\mathbf{G}}_{t} \cdot \mathbf{E}^{\prime} .
$$

In a similar manner, $\hat{\mathbf{P}}_{y}=\mathbf{E} \cdot \hat{\mathbf{P}}_{t} \cdot \mathbf{E}^{\prime}, \hat{\mathbf{H}}_{y}=\mathbf{E} \cdot \hat{\mathbf{H}}_{t} \cdot \mathbf{E}^{\prime}$, and $\hat{\mathbf{R}}_{y}=\mathbf{E} \cdot \hat{\mathbf{R}}_{t} \cdot \mathbf{E}^{\prime}$, where $\hat{\mathbf{G}}_{y}, \hat{\mathbf{P}}_{y}, \hat{\mathbf{H}}_{y}$, and $\hat{\mathbf{R}}_{y}$ are estimates of the genetic, permanent environmental, HTDr, and residual variance components of the FTIR spectra, respectively.

\section{APPENDIX B}

\section{Estimation of Variance Components for Milk Composition Traits Using the Variance Structure of the FTIR Spectra}

Let $x_{1}, x_{2}, \ldots, x_{c}$ be $c$ milk composition traits predicted from FTIR spectra using, for instance, a partial least squares regression coefficient:

$$
\hat{x}_{i}=\left(I_{N} \otimes \hat{\beta}_{P L S_{i}}\right) \cdot \mathbf{y}(i=1,2, \ldots, c),
$$

where $\mathbf{y}$ is as defined for Equation A2, $\hat{x}_{i}$ is the predicted phenotype for milk composition trait $(i=1,2$, $\ldots, c)$ and $\hat{\beta}_{P L S_{i}}$ is a partial least squares regression coefficient for trait $i$. Assume similar effects as in Equation A3, but a single-trait repeated animal model for the predicted phenotype: 


$$
\mathbf{x}_{i}=\mathbf{X}_{i} \boldsymbol{\beta}_{i}+\mathbf{Z}_{i} \mathbf{u}_{i}+\mathbf{Q}_{i} \mathbf{p}_{i}+\mathbf{W}_{i} \mathbf{h}_{i}+\mathbf{e}_{i}
$$

where all the model components are as defined in Equation A3. The following variance structure was assumed: $\operatorname{var}\left(\mathbf{u}_{i}\right)=\mathbf{A} \cdot \sigma_{a_{i}}^{2}, \quad \operatorname{var}\left(\mathbf{p}_{i}\right)=\mathbf{I}_{p} \cdot \sigma_{p e_{i}}^{2}, \quad \operatorname{var}\left(\mathbf{h}_{i}\right)=\mathbf{I}_{h} \cdot \sigma_{h t d_{i}}^{2}$, and $\operatorname{var}\left(\mathbf{e}_{i}\right)=\mathbf{I}_{\mathrm{N}} \cdot \sigma_{e_{i}}^{2}$, where $\sigma_{a_{i}}^{2}$ is the additive genetic variance, $\sigma_{p e_{i}}^{2}$ is the permanent environmental variance, $\sigma_{h t d_{i}}^{2}$ is the HTDr variance, and $\sigma_{e_{i}}^{2}$ is residual variance of trait $i$.

For any of the milk composition traits $x_{i}(i=1,2, \ldots$ ., c), variance components can be calculated from the variance component of FTIR spectra:

$$
\sigma_{a_{i}}^{2}=\hat{\beta}_{P L S_{i}}^{\prime} \cdot \hat{\mathbf{G}}_{y} \cdot \hat{\beta}_{P L S_{i}} \cdot
$$

In a similar manner, the permanent environmental $\left(\sigma_{p e_{i}}^{2}\right)$, the $\operatorname{HTDr}\left(\sigma_{h t d_{i}}^{2}\right)$, and residual $\left(\sigma_{e_{i}}^{2}\right)$ variances can be calculated using Equation B3 and replacing the respective values.

Then heritability for a trait $x_{i}\left(h_{i}^{2}\right)$ is calculated as follows:

$$
h_{i}^{2}=\frac{\sigma_{a_{i}}^{2}}{\sigma_{a_{i}}^{2}+\sigma_{p e_{i}}^{2}+\sigma_{e_{i}}^{2}} .
$$

There is no need to first predict the phenotypes of a trait and then its heritability. All needed information can come directly from spectra. 